\title{
DIGITAL OIL FIELD - FROM DATA TO REAL-TIME DECISION MAKING - SMART WORKING FOR OPERATIONS EFFICIENCY
}

\author{
Mohammad Rostami Dehka ${ }^{1}$, Iulian Nistor ${ }^{2}$ \\ ${ }^{1}$ Petroleum - Gas University of Ploiesti (PhD Student), Romania; \\ ${ }^{2}$ Petroleum - Gas University of Ploiesti, Bd. Bucureşti, no. 39, 100680, Ploieşti, Romania \\ e-mail: rostamidehka@gmail.com
}

DOI: 10.51865/JPGT.2021.01.01

\begin{abstract}
Digital Oil Field (DOF) project in OMV Petrom aims to remotely monitor, troubleshoot and optimize operations and maintenance data and activities in a modern manner, and to foster value creation through increased integrated and reliable performance data availability to skilled professionals in order to facilitate the right decisions. DOF Project started as a pilot in an oil field, covering a large area of automated wells and facilities. The pilot field is operating around 400 wells equipped with PCP (progressive cavity pump) and more than 70\% automated facilities consisting of: 14 MPSs (Meter Point Skids), 2 PMANs (Production Manifolds) and 1 OMS (Oil Metering Station), all connected to SCADA systems.
\end{abstract}

Key words: Digital Oil Field, Well Automation, Metering Point Skid, SCADA, Alarm Management, Operational Hub

\section{INTRODUCTION}

Romania has a long history of petroleum exploration, with officially registered oil production spanning over more than 150 years. Many of the oil fields discovered in the early days are still producing. Extending the production life of mature fields presents a variety of challenges including low reservoir pressure, high water cut, limited well data, aging completions and bypassed pay.

The target field is a mature field located in Moldova area, $200 \mathrm{~km}$ North East of Bucharest. The field was discovered in 1958 and exploitation started in 1959. Historically, more than 800 wells have been drilled since 1959 in this field out of which 405 wells are currently producing around 700 tons per day, $\sim 7000$ cubic meter per day gross production which translates in a water cut of more than $90 \%$ for the field. The field is the second best producer of OMV Petrom.

All the 405 wells in the pilot field have a PCP artificial lift system installed, fitted with well automation and Variable Frequency Drive (VFD) SAM units. Five wells have corrosion inhibition skids attached and two wells have an Automatic Fluid Level Monitoring System installed (MURAG 20).

The productive sands are unconsolidated so that sand control (interval gravel pack) is a prerequisite; however, it has a negative impact on the inflow performance of the wells. The wells are lifted artificially using Progressive Cavity pumps (PCP). 
OMV Petrom operates in a mature environment, where field performance management, optimum well and facilities intervention and preventive maintenance, make the difference for being "best in class" and to compete in a low oil price market environment. In today's world of compressed margins, E\&P companies are pressured more than ever to make the leap from the original design of Digital Oil Field to its full implementation in order to position themselves for the future. The Digital Oil Field is essentially bringing data to life, simplifying operations, helping to make the right decisions at the right time and thereby ensuring safe and efficient low cost operations of oil and gas fields.

\section{DIGITAL OIL FIELD PHILOSOPHY}

The DOF projects are by definition an integration challenge and as shown in Figure 1, data has to flow to the engineering panels and models, be processed automatically, and finally be visualized. Many tools and technologies from different vendors are involved, processes established and in brown fields, these new tools, technologies and processes have to co-exist nicely with the legacy systems.

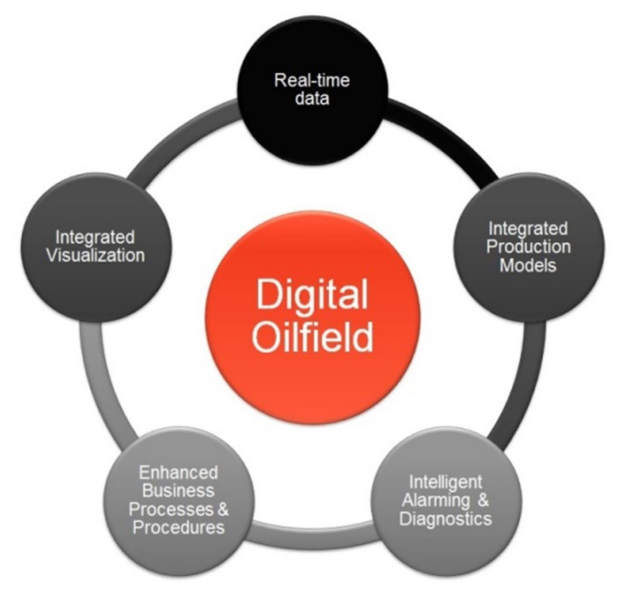

Figure 1. The concept of digital oilfield [Digital Oil Field Services, [goldenfalcon.com]

The DOF philosophy is connecting the key ingredients such as people, processes and technologies that are required to efficiently operate oil and gas fields. Increasing people's skills, shaping processes and organization for full value generation from implemented automation systems and technologies represent the foundation of sustainable high level performance.

The application of digital technology certainly involves deploying hardware, sensors, and information management systems; however, considerable efforts go towards developing globally standard asset management processes, as well as ensuring that organization has the knowledge, resources, and capability to fully leverage those processes. Applicable technologies are systematically evaluated and applied, enhancing the organization's capabilities to make better decisions, faster. Undoubtedly, technology is significantly more valuable when assessed by skilled people using standard global asset management processes. In the course of DOF implementation in OMV Petrom the effort was to develop these three key pillars of business transformation with all the major elements connected to the pillars, as depicted in Figure 2. 


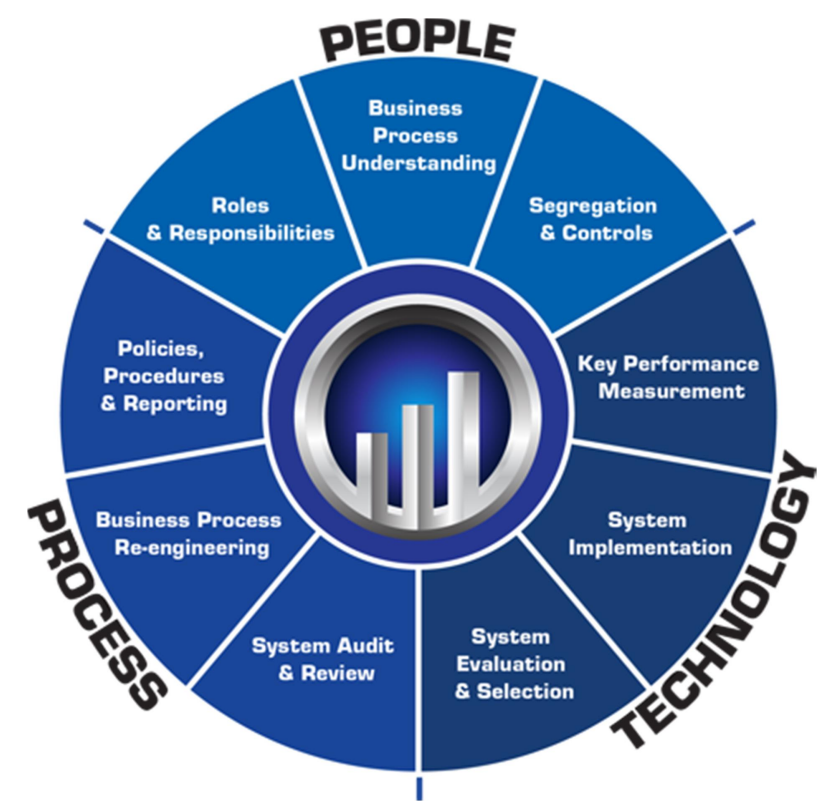

Figure 2. Three key elements of operational excellence in DOF project [https://fitechgelb.com/, http://syuttechnologies.com/]

\section{PEOPLE AND ORGANIZATION}

For OMV Petrom, the digital oilfield implementation phase is not only the deployment of the developed and configured solutions, it is the best opportunity for deeply embedding the solutions into the day-to-day operations, and establishing privileged contact with the engineers who will be the end users of the solutions. Therefore, all deployments are executed by skilled domain experts, automation, petroleum, chemical or electrical engineers. They deploy the solution with the business challenges in mind, ensure the training of their peers and remain available for support.

At OMV Petrom, in particular the above mentioned automated oil field, operators and engineers in the field, sector and Asset HQ, are specialized in understanding the key business challenges, and propose fit for purpose solutions, exploiting the best in class technology in the market to maximize the value of assets. Company provides courses and on the job trainings on specific tools and on the integrated solution, made out of different vendor's packages. The training sessions are given by experienced and skilled engineers, who understand the day-to-day challenges that the end-users are facing.

Despite all our technological advances, people are still core to business success. Using technology and re-imagining processes requires strong leadership, a community of advocates and, in some cases, a center of excellence in analytics.

\section{PROCESS}

As mentioned, the three cornerstones for adoption of digital oilfield projects are people, processes and technologies. The technology-measurements, telemetry and data access has matured immensely in the last few years. However, the data is not fully utilized due to the lack of processes as well as the shortage of skilled manpower across the organization. Therefore, there was a focus during DOF implementation and roll out for other onshore Assets in OMV Petrom shifting towards developing processes to integrate real-time data and alarm management measures in production optimization workflows. 
OMV Petrom processes for day to day operational activities is addressed in DOF project, as shown in Figure 3, which include monitoring of automation systems, alarm management matrix, incident communication with mobile team, troubleshooting and resetting of systems parameters, optimization for automation requirements, updates and integration to increase the uptime of the wells and facilities to increase efficiency and recovery of the assets.

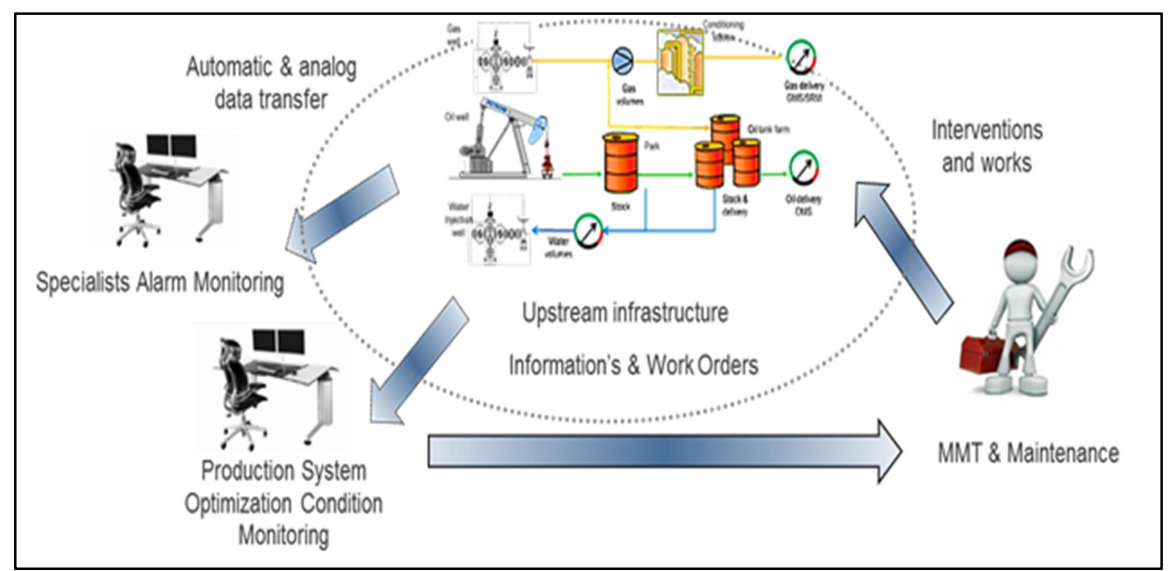

Figure 3. DOF working processes, - foundation for proper functioning of the automation systems [OMV Petrom DOF Project]

In line with the work processes for all automated facilities in OMV Petrom, an overall process is established in which the roles and responsibilities of different divisions and expertise are recognized for all automated wells and facilities as shown in Figure 4 and a detailed work process is developed for each automation project. The real time alarm management of the automated systems is monitored through a central room in the respective field Asset HQ which is called "Operational Hub".

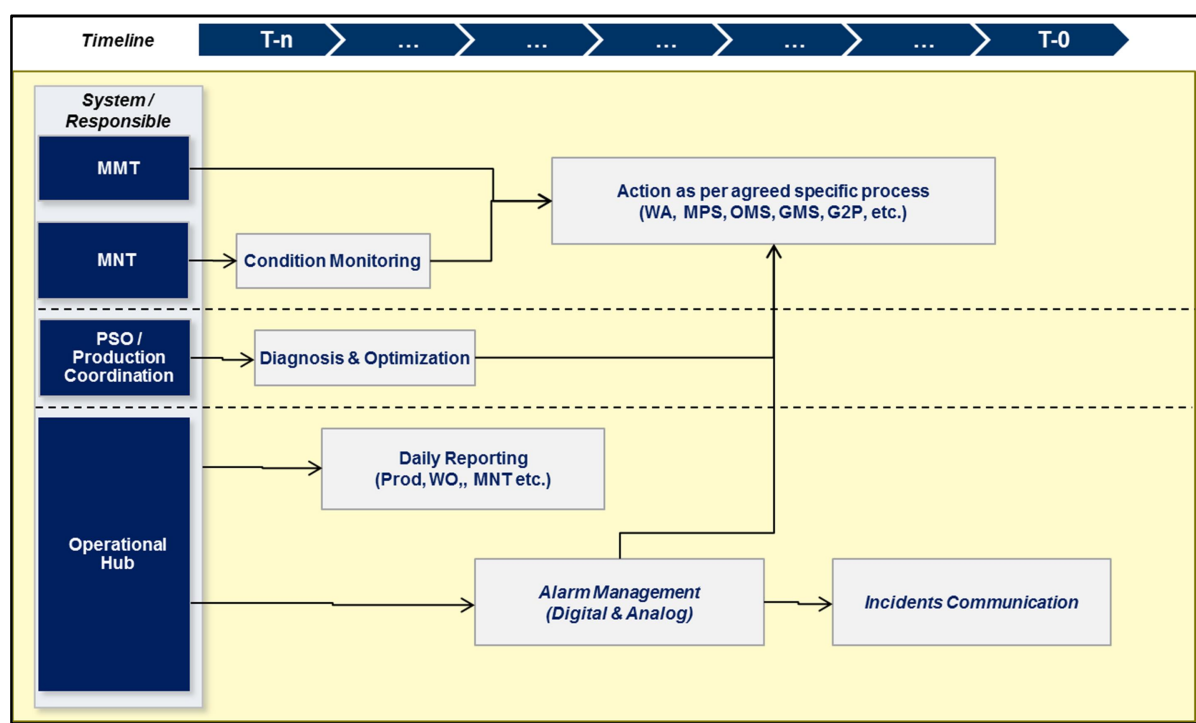

Figure 4. Overall process for OMV Petrom automated and analogue systems [OMV Petrom DOF Project] 


\section{TECHNOLOGY}

OMV Petrom is continuously focusing on modernizing and optimizing the operations, therefore new technology testing and implementation is a very important activity for the company. OMV Petrom has a dedicated program for new technologies, organizing annual forums to screen the industry for modern applications. Several operational and information technologies have been evaluated and implemented in OMV Petrom automation projects and some of these technologies are summarized in the next section:

\section{Fluid Level Measurement}

The MURAG-20 device is a unit used to measure the fluid level of a well based on sound data sampled from wells equipped with this tool. The integrated acoustic monitoring of MURAG-20 device for noise pattern recognition can be used for condition monitoring of down hole equipment which allows detecting abnormal conditions such as valve function, tubing leak, rod buckling, etc. The system will support continuous and automatic adjustments of artificial lift systems such as SRP, PCP, ESP (oil production and gas well deliquification), as shown in Figure 5, which also shows the main components of MURAG-20, listed below:

a) Transducer

b) Analyzer

c) Signal processing

d) Measure of the fluid level

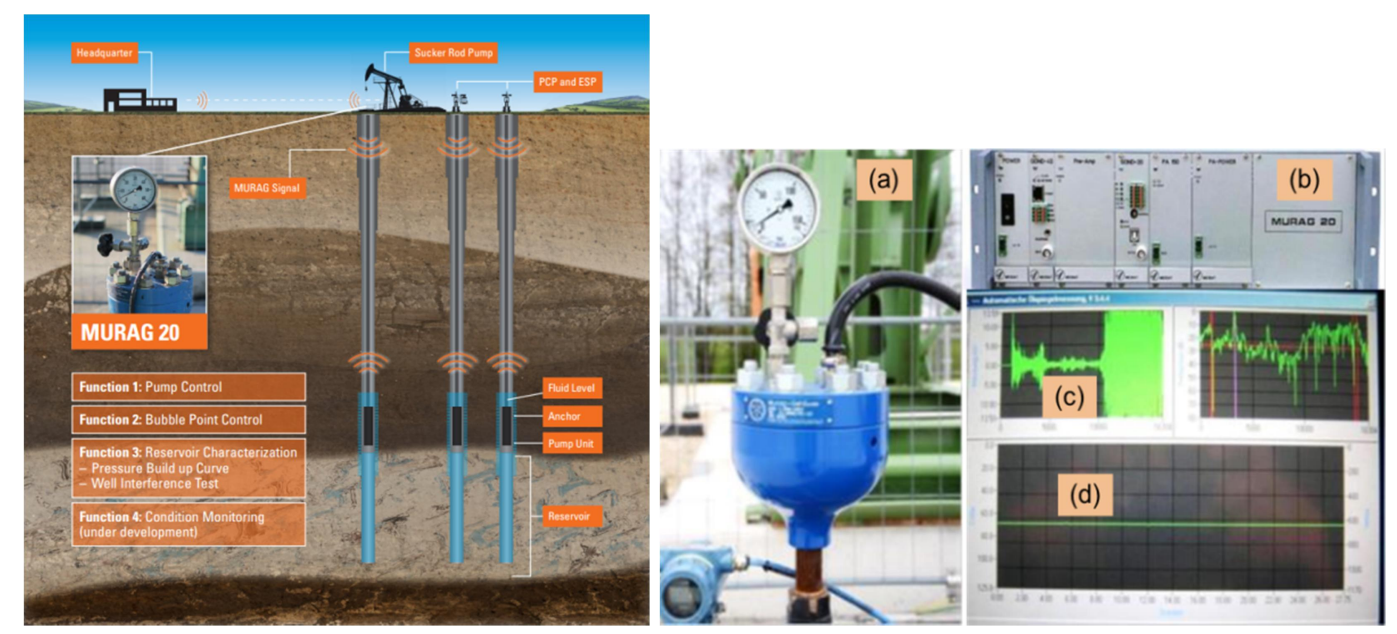

Figure 5. MURAG-20 for all types of pumps with multiple functionalities and main components [RAG.AUSTRIA.ENERGIE - http://www.alrdc.org/, SPE 145434]

\section{Flow Meter}

In OMV Petrom Wedge Meter flow meter has been installed downstream of the automated wells in the pilot project to measure well gross production rate, as shown in the upper part of Figure 6 which also shows the measurement mechanism of differential pressure Wedge meter in the lower part. 
Wedge meter is a differential pressure (DP) type of flow meters which is one of the most commonly used groups of flow meter. The DP meter can be used in one or two ways. It can either be used to calculate the flow rate of multiphase mixture or, if you already know the flow rate, you can use the DP device to derive the fluid density.
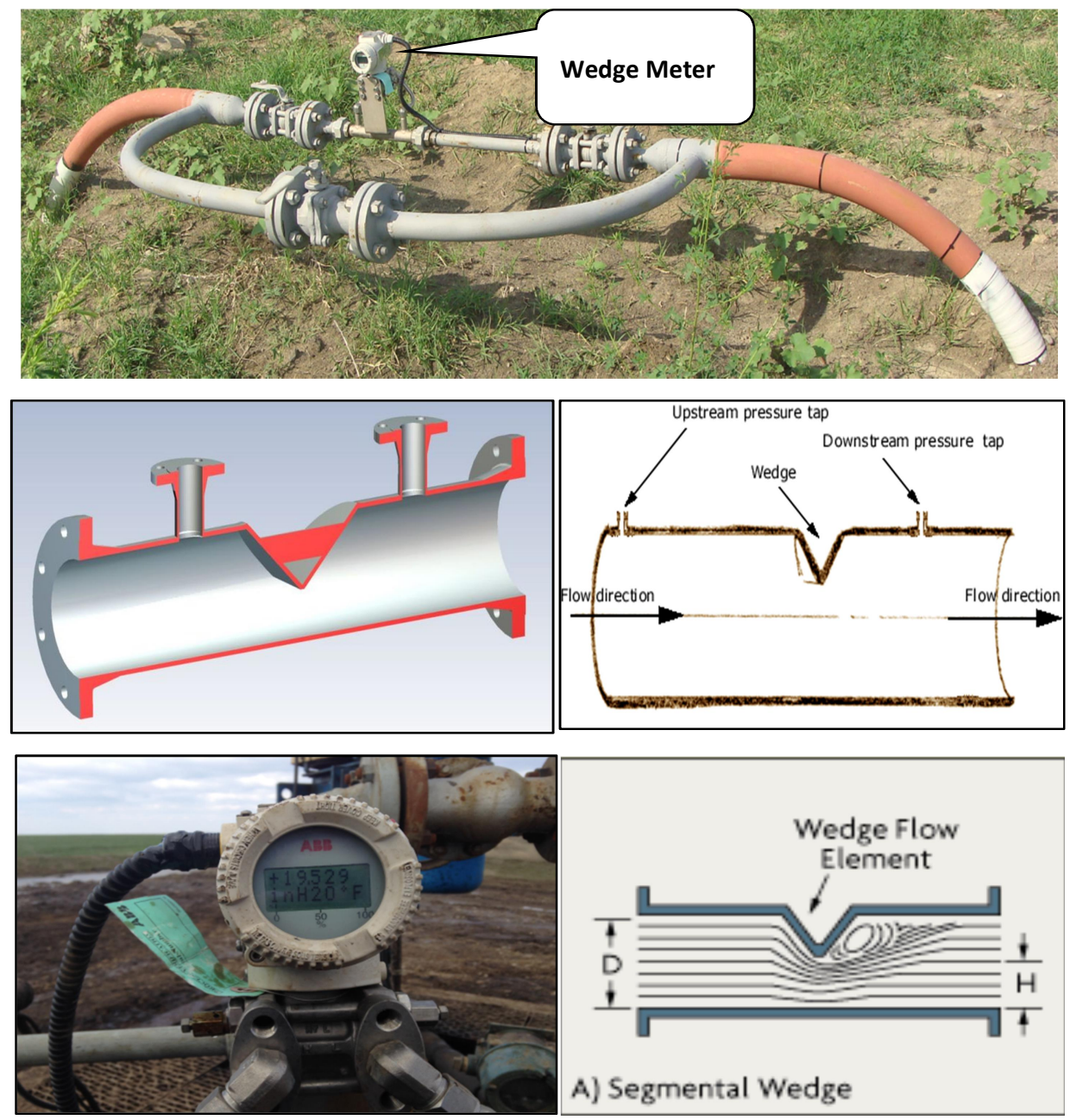

Figure 6: Mechanism of differential pressure Wedge meter

[OMV Petrom DOF Project \& www.omega.co.uk, http://www.emcocontrols.com/]

\section{ALARM MANAGEMENT PHILOSOPHY}

The alarm philosophy documents OMV Petrom Upstream's approach to alarm management. It specifies the criteria, definitions and principles for an alarm system, in line with international best practices and is related to the lifecycle of alarm management will address the following topics:

What is an alarm?

Roles and requirements

Rationalization requirements

Alarm class definitions, design, requirements

Alarm priorities, definitions, etc. 
Alarm shelving / suppression rules

alarm system monitoring requirements

management of change

training

The purpose of the alarm philosophy is to ensure that effective alarm management systems (based on best practices for alarm management) are implemented and maintained at all OMV Petrom Upstream onshore automated facilities. An effective alarm management system is one that acts as a tool to help the operator to take always the correct action at the correct time.

The following are the key assumptions made in the alarm management philosophy:

a) no amount of alarm management will replace the constant surveillance of a qualified operator.

b) operational hub personnel and operators are to be trained on the alarm management strategy.

c) operational hub personnel will respond to all alarms, regardless of priority.

ISA-18.2 alarm management standard was implemented in OMV Petrom DOF project which is written with a 10-stage life-cycle structure (Sections 1 to 10). These are not activities. Life cycle is a document structure for organizing requirements and recommendations, not a project plan for improving an existing system

The lifecycle of alarm management, as shown in Figure 7 below.

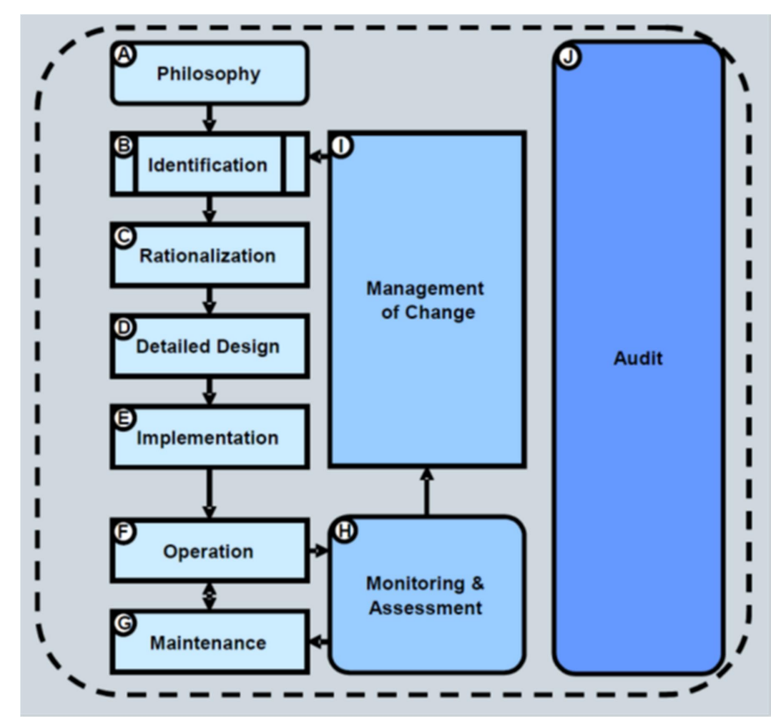

Figure 7. The Alarm Management Life Cycle [www.isa.org , ISA 18.2]

\section{WELL AUTOMATION PROJECT (WAP)}

The aim of Oil Well Automation is to monitor and optimize the function of artificial lift systems remotely to increase lifting efficiency and run life of surface and down whole components. The mature environment of OMV Petrom fields necessitates such artificial lift systems on $95 \%$ of oil wells in order to bring up hydrocarbons to surface. 
To test automation philosophy on well level, a pilot project was initiated in 2009 for a group of 60 wells in a few oil fields. After successfully piloted WAP and very good results, OMV Petrom decided to widen rollout of the technology despite low oil price environment for the previous 3 years and this was started during 2011. The rollout was planned to be done in 4 steps / phases with clear actions: identification of new candidates, analyses the well data from technical and economical point of view, implementation of the technology and check of the results. Thereby, until 2017, 4000 oil wells were completed with automated systems. In the same time, the technology of the monitoring system was checked and rollout on the $\sim 300$ water injector wells with good results too.

As depicted in Figure 8, all wells are linked via data transmission to a monitoring and pump optimization software package allowing real time access to current operating conditions, as well as trending of historic short-term and long-term parameters. dedicated artificial lift engineers are constantly monitoring and optimizing well parameters via central locations.

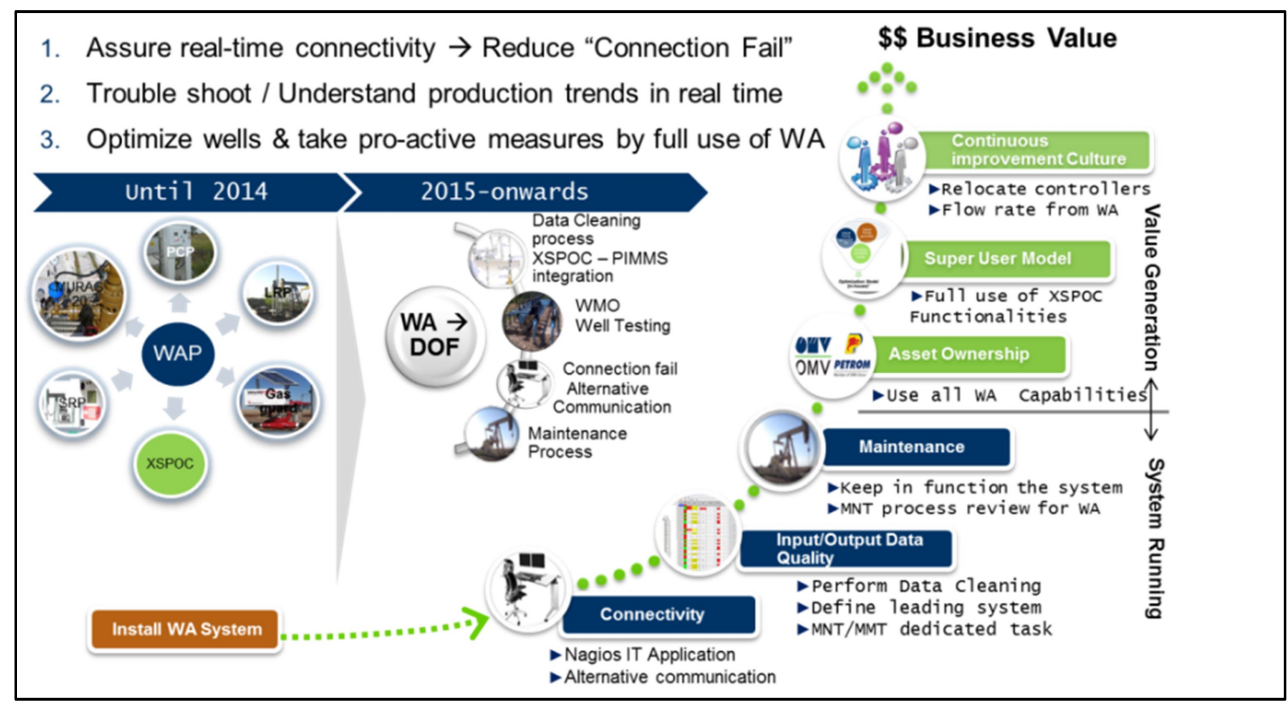

Figure 8. Well automation project-optimization in real-time [OMV Petrom DOF Project]

Technological advancement has generated more information and data available that should be well tracked and allows experts to optimize the well-functioning. In order to realize a "Full Value Chain", the new strategy was developed in 2016 for Well Automation empowerment, which combined data connectivity and accuracy improvement, well modeling and specific key performance indicators (KPIs) that could be applied widely across all domestic assets from OMV Petrom.

Thereby, the data connectivity issue between servers and well automation equipment's was significantly reduced in 2016 up to $3 \%$ by a joint team effort between Vodafone and OMV Petrom through extension of Vodafone network capacity and implementation of a new infrastructure monitoring tool (NAGIOS). This helped OMV Petrom to maximize the performance connection. 
PCP Automation Systems in the pilot project are installed with the standard pump off controller which is equipped with VSD (Variable Speed Drive). This system enables an automated variation of pump speed instead of switching off the electric motor.

The PCP controller is a pre-programmed device mounted at the well site that gathers, processes, stores; and analyses data obtained from transmitters and meters. The data collected from these input devices is used to monitor and control pump operation to maximize fluid production efficiency and protect the pump.

PCP controller utilizes an algorithm specifically designed to control speed and torque for PCP applications.

In OMV Petrom DOF pilot project, PCP unit's automation is implemented on more than 405 wells to perform the following tasks:

$>$ PCP controller to optimize production of the well avoiding pump off or torque issues

$>$ control is achieved by monitoring flow rate and adjusting

Figure 9 represents a schematic of well status in PCP well through SAM controller and PCP performance monitoring in real-time.
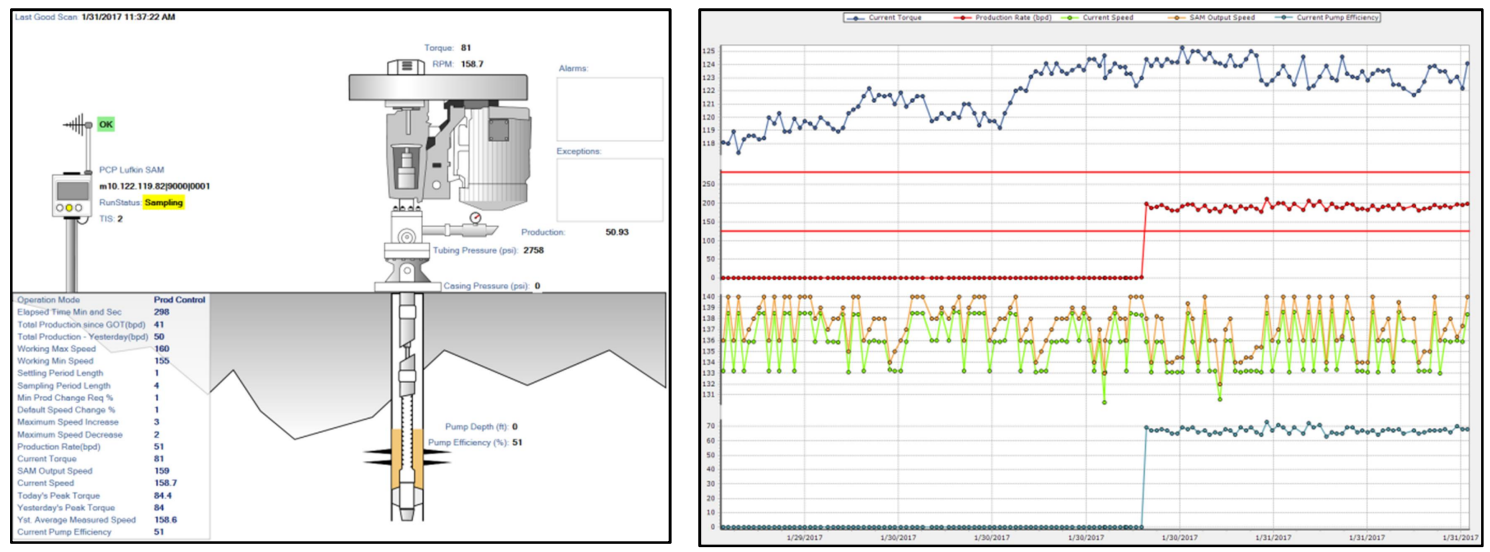

Figure 9: Well status in PCP well through controller and pump performance monitoring in real-time [OMV Petrom DOF Project]

\section{AUTOMATED SURFACE PRODUCTION FACILITIES}

Metering Point Skids (MPSs) are designed to replace gathering facilities, which are in terms of current production level and footprint oversized, with automated fit-for purpose skids. MPSs are used to measure the production volumes as depicted in Figure 10. Relevant operational and maintenance data are SCADA integrated. Figure 8 represents a MPS and the alarm management workflow.

Most of the automated facilities are controlled by one or more automation systems, providing a wealth of data to the SCADA system, data that can be used to monitor nearly every aspect of wells and facilities' operations. With modern automation and SCADA systems, the condition of all the relevant operating parameters can be displayed on a screen. Deviations from normal operating envelopes are indicated with alarms which trigger the intervention by mobile teams in the field. 

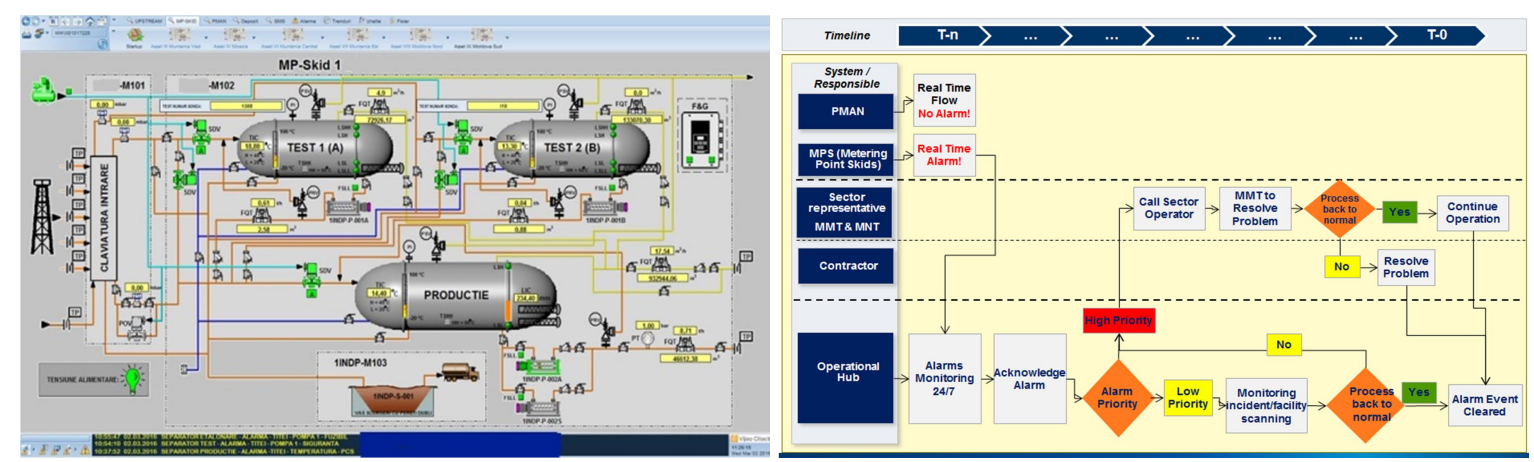

Figure 10. MPS and alarm management workflow [OMV Petrom DOF Project]

\section{CONCLUSIONS}

The Digital Oil Field in OMV Petrom consists of the following main components:

$>$ operational HUB

$>$ automated surface production facilities

$>$ well automation

This enhanced operational set up delivers significant benefits:

$>$ safe operations through real time online monitoring of well and facility condition parameters

$>$ reduced onsite exposure and windshield time for field staff

$>$ minimized production losses/ deferments

$>$ improved production potential utilization and efficiency

$>$ avoidance of damage of subsurface/surface equipment through monitoring and optimization

$>$ increased run life of equipment, energy consumption per BOE (barrel of oil equivalent) of oil produced, optimized oilfield chemical usage and thereby significant reduction of operating costs.

Based on the results already obtained during the Digital Oil Field, the project of excellence in automation is launched in all 8 onshore assets of OMV Petrom Upstream.

\section{REFERENCES}

[1] Cramer, R., Gobel, D., Mueller, K., "A measure of the DOF status-is it the end of the beginning", SPE 149957, presented at SPE Intelligent Energy international, Utrecht, Netherlands, 27-29 Mar. 2012.

[2] Sam, G., Kaestenbauer, M., Burgstaller, C., Chevelcha, E., “ Fully Automated Fluid Level Measurement Tool”, SPE 145434, presented at SPE Asia Pacific O\&G Conf., Jakarta, Indonesia, 20-22 Sep. 2011.

[3] Dudley, G., Perry, J., Goodwin, S.: "The challenges of implementing at scale: Field of the future-Technologies in the North Sea", SPE 99829 presented at 2006 SPE Intelligent Energy Conference and Exhibition" Amsterdam, The Netherlands, 11-13 April. 
[4] Alkhadhuri, S., Narasayamy, D., Sheik-Mohamed Sheik Said: Integration of people, process and technology for right-time production optimization in Brunei", SPE 99243 presented at the 2006 SPE Intelligent Energy Conference and Exhibition" Amsterdam, The Netherlands, 11-13 April.

[5] OMV Petrom Internal Report, "Automation Excellence Project", Petrom City, Bucharest, 2016.

[6] OMV Petrom Internal Report; "Well Automation Project as part of Digital Oil Field", OMV Petrom HQ, Bucharest, 2017.

[7] OMV Petrom Internal Report; “Automation Excellence Project”, OMV Petrom HQ, Bucharest, 2017.

[8] OMV Petrom Internal Report; "Gas Facilities Automation Project”, OMV Petrom HQ, Bucharest, 2017.

[9] RAG Austria: "Newly developed automatic fluid level control system, MURAG 20”, Gas Well Deliquification Conference, 28-29 Sep, 2011.

[10] Lufkin: "Wedge type Differential Pressure, Well Automation System Wedgemeter configuration, maintenance, handling", Petrom Partner Reports, Bucharest, 2014-2016.

[11] SEKO: "Chemical Injection Skid, Automation Package", 2014-2016.

[12] Theta: "XSPOC SCADA User and Administrator Manual", 2016. 